\title{
The Role of Active Musical Listening to Enhance the Emotional Health on Early Motherhood
}

\section{Djohan}

Music Performance Department of Indonesia Institute of the Arts Yogyakarta, Indonesia Email: djohan.djohan@yahoo.com

\section{Fortunata Tyasrinestu}

Music Education Department of Indonesia Institute of the Arts Yogyakarta, Indonesia

Email: tyasrin2@yahoo.com

\begin{abstract}
The purpose of this study was to identified the role of active musical listening on emotional health and well-being in Javanese early motherhood. Listening to music will not only have a soothing and uplifting effects on someone but also a positive influence on the unborn baby. Feeling emotional during pregnancy is common because of hormonal changes. And it's natural to feel more stressed or anxious than usualy. Although it's normal to have periods of worry and stress when pregnancy and this can be a sign of something more serious such as depression, anxiety or bipolar disorder. Emotional health is a state of wellbeing. An one way anova test with the pre-posttest scores as the control revealed that the changes by listening the gendhing gamelan were significantly decreased in the experimental group compared with the control group. A randomized experimental study design was developed and implemented. A hundred and twenty of first trimester pregnant women were randomly assigned to music listening $(n=60)$ and control $(\mathrm{n}=60)$ groups (mean age $=29.0 ; \mathrm{SD}=5.0)$. The experiment group received 5 minutes of music intervention and the control group received only general prenatal care. Psychological health was assessed using three self-report measures: State-Trait Anxiety Inventory (STAI) and Beck-Depression Inventory (BDI). The result shows significant effect $(\mathrm{p}<0.05 ; \mathrm{F}=5.340)$ of gendhing gamelan to reduce stress and enhance the emotional well-being in early motherhood thus the hypotheses is accepted. The findings can be used to encourage early motherhood to use this cost-effective method of listening music in their daily life to reduce their stress and enhance the emotional wellbeing. Further research is needed to test the long-term benefits.
\end{abstract}

Keywords: emotional health; well-being; music listening; gendhing gamelan

\section{INTRODUCTION}

In Indonesia, the death rate of mother and infant stay at a high level every year even it has reached 4.000 deaths per year. Various efforts has been applied by government, health center, hospital and posyandu (Pos Pelayanan Terpadu: is a 
kind of a free service center in Indonesia that facilitated by a local government mostly in rural region for medical examination especially intended to an early motherhood, pregnancy, post-natal and new born till toddler) mainly to cope with the obstacles related to this case. Perinatal mental health problems affect around $20 \%$ of women at some point during the perinatal period ${ }^{[1]}$. The mentioned services can be applied earlier from the early until late pregnancy even postnatal period. And over the last two decades, there has been significant research into the emotional health on pregnant mother as well as how it can be prevented.

In the wider population, depression and well-being are separate constructs in the context of perinatal mental health and a positive perinatal experience is more than simply the inversion of negative mood. Pregnancy period requires woman to have preparation physically and mentally due to physical and hormonal change that prone to generate anxiety. Biologically, the increasing of progesterone and estrogen coupled with psychological state then result some women feel depressed of the change and try to neglect the fact of their pregnancy.

Most woman in pregnancy period experienced many distress mainly caused by the change of emotion, physic, and environment ${ }^{[2]}$. In particular, the third trimester of pregnancy has been identified as an important transition period involving adaptation to emotional and physical changes, leading to feelings of well-being often less pronounced than in the previous trimesters ${ }^{[3]}$. In light of this, there are a number of interventions that have been developed to try and support mental health in the prenatal period as a way of reducing postnatal mental health problems, in particular focusing on the third trimester as a point of intervention. There have been findings that support the application of cognitive-behavioural and interpersonal psychotherapy, suggesting that depression following childbirth could be prevented by brief interventions in the prenatal period ${ }^{[4]}$. Another problem following pregnancy is libido issue that is need to be communicated between spouses. Even though some physical reactions during pregnancy, such as breast enlargement, is something common, most anxiety in pregnancy is caused by the mixture of happy and sad feeling, hesitation and conviction, and morning sickness. That is why we can assume that most of pregnant women experience psychological changes.

Over the past two decades, there has been increasing research showing the effects of listening to music on mental health. A number of reviews have demonstrated the effects of regular music listening including in enhancing mental health in the general population, reducing distress in premature infants and reducing stress in adults ${ }^{[5]}$. Unstable emotion is usually followed by mood changes such as being sensitive and overreacting with the result that the mental condition in vulnerable. This vulnerability might be caused by the gap between what is felt physically and what is understood mentally. Thus, pregnant woman tent to depend 
on other individual or being too demanding in this period. Another way to handle the discomfort during pregnancy is through the external factor that is one of human potency: music.

Many attempts and research be done to help woman in facing pregnancy period showed significant decrease of stress and anxiety to a group of mother that received 30-minutes music session out of health program. In relation to well-being, music listening has been shown to be associated with better well-being not just in controlled interventions but also as a result of ordinary day-to-day listening. A Swedish study involving 500 older adults found associations between music listening and well-being, even when controlling for potential confounding variables ${ }^{[6]}$.

Thus, this research aim to identify the role of listening Gendhing Gamelan to enhance the emotional health and well-being in pregnant women to discover its specific effects on psychological issue which are expected to support mental health in pregnant women that will implicate in fetus' mental health. We hypotheses (1) pregnant women be intervened by music will have more relax compare to control group, (2) pregnant women be intervened by music will have less stress compare to control group.

In the perspective of anesthesia expert, music is claimed to be useful in Csection to strengthen anesthesia effect that is mostly without narcotics to make sure the infant won't be depressed. This labor preparation involving physical manipulation is prone to generate discomfort in mother thus music is believed to be effective in reducing the discomfort. In early pregnancy, stress overreacting create a negative effect during pregnancy. Most of the physiological stress is mediated by stress hormonal named catecholamine. In pregnant woman, level of stress can reduce uterine contraction effectiveness and over anxiety is associated to fetal death in third trimester ${ }^{[7]}$. Music is able to control respiratory rate and reduce stress response thus music can help to shorten the labor process ${ }^{[8]}$. Another research suggests that music reduce pain when it is heard ${ }^{[9]}$.

Studies tracking daily activities have linked music listening with enhanced well-being both in the workplace and in the wider context of people's lives ${ }^{[10]}$. Studies tracking daily activities have linked music listening with enhanced wellbeing both in the workplace and in the wider context of people's lives. Further, music has also been shown to contribute to creating supportive healthy environments, connecting individuals with their emotions and promoting wellbeing ${ }^{[11]}$. The environment of prenatal period is also has its own impact toward fetus. Many physical stress and emotion during pregnancy will influence the abnormality in baby and inhibit the development of motoric function [12][13]. Globally, teenage pregnancy remains a public health concern. Worldwide, sixteen million girls give birth during adolescence annually with an estimated 
three million having unsafe abortions. Most adolescent pregnancies occur in developing countries, and teenagers living in socio-economically disadvantaged settings in developed countries are at higher risk of teenage pregnancy as compared to the broader population ${ }^{[14]}$. Further, listening to music is can improve learning ability ${ }^{[15]}$, reduce bold pressure, improve the epilepsy symptoms, Parkinson disease, and dementia ${ }^{[16][17]}$.

\section{Theoretical Framework}

Theoretical studies have highlighted the role of music listening in enhancing affect, wellness and resources for recovery and quality of life. Consequently, both directed music listening interventions and routine day-to-day music listening can affect levels of depression and well-being in a range of different populations ${ }^{[18][19]}$. Likewise the exposure of noise during pregnancy, it can disturb the brain development in baby and harm the cognitive function ${ }^{[20]}$.

To maintain the balance of chemical in pregnant woman, there are four main hormone that mostly works; endorphin, dopamine, serotonin, and oxytocin that are contributing in positive feeling as a dimension of happy feeling. Dopamine and endorphin work as selfish chemical that is produced when someone is struggling to achieve something. Endorphin works by manipulate pain through happiness of euphoria. It happens for example when someone win a competition. Later, dopamine works by affecting the blood and generate a satisfaction.

Meanwhile, serotonin and oxytocin is more external chemical that is generate a proud feeling because of being loved by a group or relatives such as parents, spouse, or children. This study tracked a cohort of mothers in the early perinatal period in order to ascertain whether there was a relationship between music listening during pregnancy and the enhancement of mental health. However, this experiment did not look longitudinally and only involved the first trimester pregnant as an early motherhood.

\section{MATERIALS AND METHODS}

The design used in this research in non-equivalent control group nonsynchronized as an attempt to discover the role of listening Gendhing Gamelan to the enhancement the emotional health and well-being. In this paper, we use the terms early motherhood for the subject as a young pregnance woman (mean=29 years old). All of the 60 young women who participated in this study were early motherhood at the time of their first pregnancy. 
Djohan $^{1}$; Fortunata Tyasrinestu ${ }^{2}$, The Role of Active Musical Listening ...

\begin{tabular}{|llllll|}
\hline Group & Pretest & Posttest & Pretest & Experiment & Posttest \\
\hline $\begin{array}{l}\text { Experiment } \\
\text { Control }\end{array} \quad$ Yb1 & Yb2 & Ya1 & $\mathrm{X}$ & Ya2 \\
\hline X = music; & Ya1, Yb1: STAI and BDI; Ya2, Yb2: STAI and BDI \\
\hline $\begin{array}{l}\text { STAI = State } \\
\text { gending }\end{array}$ gamelan Anxiety & Inventory; & BDI = Beck Depression Index; X = \\
\hline
\end{tabular}

\section{A. Subjects}

The subject in this research was determined incidentally. It consists of 60 early motherhood (experiment $=30$; control $=30$; mean age $=29.0 ; \mathrm{SD}=5.0$ ) in Puskesmas (Pusat Kesehatan Masyarakat: the health center for local society) at Kotagede, Yogyakarta.

\section{B. Instruments}

1) STAI

State Trait Anxiety Inventory is a quick and short measurement of state and trait of anxiety to acquire high result for technical use ${ }^{[23]}$. State anxiety is a temporary condition of fear or anxiety mainly experience in a particular event. Trait anxiety is a relatively stable tendency of a human to respond a stimuli in anxious way and prone to generate distress. Those two aspect seems different yet interrelated to one another. The level of trait anxiety reflects the inclination to show anxiety and stress in human. STAI consists of 40 items to measure the two types of anxiety in separable way. STAI item is simple and descriptive consist of 20 state anxiety items measured on 4 intensity scale: "not at all", "sometimes", "kind of", and "very anxious". It also consist of 20 trait anxiety items measured on 4 intensity scale: "never", "seldom", “often", and "always".

2) $\mathrm{BDI}$

Beck-Depression Inventory is a self-report rating inventory consisting of 21 items to measure characteristic attitude and symptoms of depression ${ }^{[24]}$. This instrument is used as a control to strengthen the first instrument, STAI. Not only anxiety, previous research reported prevalence of depression among pregnant women ${ }^{[26]}$. We assume high level of anxiety will lead into depression. Thus, if the BDI index shows a decrease level, it might be assume that the anxiety level is also decrease. BDI consist of 21 items on scale of 0-3 indicating the symptoms of depression such as hopelessness and irritability, weight loss, appetite, interest in sex, fatigue, and even cognitive aspect such as guilt of feeling of being punished. Each number consist of four statements of a topic in a different scale and respondent will answer the most suitable scale to define their condition. 


\section{Auditory Stimuli}

The audio stimuli of this research is 15 minutes gendhing gamelan in slendro sanga scale with title Gadhung Melati that is heard by the subject through a wireless headset in a medium volume (3-5) to make sure that the audio can be heard clearly but not too loud for the hearing. Gendhing gamelan Gadhung Melati was chosen for a treatment to the experiment subject as an auditory stimuli because of its intrinsic characteristic that is calm and relaxing. It is also because not many research in this area uses gendhing gamelan as its main stimuli.

\section{Procedure}

All of experiment subject are informed about the research and have consent to participate in this data collecting. After filling the pretest questionnaire, subjects are directed to the listening room. The experimenter need to make sure the subjects are relax and comfortable during listening section thus the subjects are allowed to sit or nap on their own choice. Another instruction be given to respondents included (a) relax and put the most comfortable position, (b) allowance to close their eyes and (c) not to do unnecessary activity such as to operate cellphone. The headset is installed under the consent of the subject considering their comfort. After listening the music for 15 minutes, we asked the subjects to fill the post test questionnaire. While the control subject just have a routine monthly medical check in a different room.

\section{RESULTS}

Before go to further analysis of the experiment, we present the comparison data of both control and experiment group in pre and posttest.

\begin{tabular}{|l|c|c|c|c|}
\hline \multirow{2}{*}{ Variable } & \multicolumn{2}{|c|}{ Control Group } & \multicolumn{2}{c|}{ Experimental Group } \\
\cline { 2 - 5 } & Pretest Score & Posttest Score & Pretest Score & Posttest Score \\
\hline $\mathrm{N}$ & 30 & 30 & 30 & 30 \\
\hline Minimum & 3 & 5 & 3 & 3 \\
\hline Maximum & 62 & 55 & 64 & 97 \\
\hline Mean & 26.83 & 27.33 & 26.77 & 37.80 \\
\hline
\end{tabular}

The table above shows the minimum score of control group is 3 with maximum score 62, meanwhile experiment group's minimum score is 3 with maximum score 64. Mean value of control group is 26.83 and mean value of experiment is 26.77. Here we can see the higher mean of experiment group 0.06 . To examine if both groups are similar to each other we applied a t-test. 
Based on the t-test, both groups are considered homogenous if the significance coefficient $>0.05$. In contrast, if the significance $<0.05$ the sample of both group is not homogenous. The result of t-test on Equal Variances Assumed column showed significance as big as 0.987 . Thus, both subject in control and experiment groups are homogenous and have similar stress level before the experiment.

On posttest data the minimal score of control group is 5 and the maximum score is 55. Meanwhile experiment group have minimal score of 3 and maximum score of 97. The mean value of control group is 27.33 and mean value of experiment group is 37.80 . The comparison above shows that experiment groups that listening to Gendhing Gamelan have better performance in reducing anxiety. This can be seen from the mean value increasing. The control group's mean increase 0.5 from 26.83 to 27.33 meanwhile the experiment group's mean increase 11.03 from 26.77 to 73.80 . To do a different test using independent sample t-test, we need prerequisite test that are normality and homogeneity test. Normality test is needed to ascertain data distribution, whether it is normal or it isn't. Homogeneity test is needed to ascertain data homogeneity. Normality test is done with Shapiro-Wilk test on SPSS. The data is normally distributed if the significance coefficient $>0.05$.

Kolmogorov-Smirnov result showed that the posttest score of control group sign. 0.166 meanwhile experiment group sig. 0.200. Both significance coefficient is $>0.05$ thus can be assumed that data in both group is distributed normally. Homogeneity test is done by Levene Statistic test. The data is claimed to be homogeny if sig. $>0.05$. The result of homogeneity test with SPSS showed sig. value $0.378>0.05$ thus the posttest data is homogenous.

Independent sample t-test is used to ascribe the different on anxiety level between control and experiment group. These two group is considered different $f$ the sig t-test for Equality of means $<0.05$. In contrast, if the value of sig. t-test for Equality of Means $>0.05$, both groups are assumed to be similar. Based on the result, t-test for Equality of Means on df 58 sig. $0.024<0.05$. It can be considered that there is different level of anxiety of control and experiment group. The experiment group have lower anxiety level than control group. Here we can conclude that gamelan is enable to reduce anxiety and no depression in pregnant woman.

Further, to ascribe the effect of gamelan in reducing anxiety level in pregnant woman, we use One Way ANOVA. Through this analysis, we will examine the effect of independent variable, gamelan, in reducing anxiety as the dependent variable. In this analysis, independent variable is considered to take effect on dependent variable if it fulfilled two criteria: (1) F is bigger than F table and (2) sig. value $<0.05$ 
The ONE way ANOVA result can be seen in table below:

Posttest Psychologically Anxiety dan Psychiatry

\begin{tabular}{|l|l|l|l|l|l|}
\hline & Sum of Squares & \multicolumn{1}{c|}{ df } & \multicolumn{1}{|c|}{ Mean Square } & \multicolumn{1}{c|}{ F } & \multicolumn{1}{c|}{ Sig. } \\
\hline Between Groups & 1643.267 & 1 & 1643.267 & 5.340 & .024 \\
Within Groups & 17847.467 & 58 & 307.715 & & \\
Total & 19490.733 & 59 & & & \\
\hline
\end{tabular}

The table above showed F 12.404 with sig. 0.001 . In F table with df 58 sig. 0.05 we get $\mathrm{F}$ table 4.01. The value of F 5.340 is bigger than $\mathrm{F}$ table 4.01. Moreover, the significance $0.024<0.05$. Thus, we can conclude there is significant role of listening to gendhing gamelan to reduce the anxiety and enhance the emotional well-being in pregnant woman. However, motherhood also brought some mixed feelings and experiences. Pregnancy at any age can be physically exhausting and for young women who are often 'alone' or with little support which physiologically and emotionally still developing, pregnancy can be challenging and bring feelings of joy to these early motherhood.

\section{DISCUSSION}

Motherhood, however, also brought some mixed feelings and experiences. Pregnancy at any age can be physically exhausting and for young women who are often 'alone' or with little support, and physiologically and emotionally still developing, pregnancy can be challenging. Statistical analysis above showed the relation of listening to Gadhung Melati and anxiety reduction in pregnant women. The result of homogeneity test showed that subject in experiment group tent to receive same effect from listening Gendhing Gamelan. Based on what happened in the data collection process, we found some respondent in experiment group that was not really focus and pay attention during music listening. Some of them broke the procedure of listening by playing their cellphone for a minute or two during the listening session.

Another respondent came with their children and tent to less focus compared to the respondent without children because they had need to pay attention to their children. Some respondent seemed less enthusiast in answering posttest questionnaire and tent to answer fast without really try to make it sure. When the statistical analysis stated the homogeneity in experimental group in terms of listening and its ability to reduce anxiety, we need to discuss this result under the consideration of respondent different intention in doing the task. 
If in fact music listening need a proper focus and attention to gain the benefit, then what define the less focus respondents should be a rationale in criticize the instrument used to measure the anxiety or to reconsider whether selfreport is proper enough to prevent random answer put by respondent in order to show difference before and after listening without really fell the difference in real. In other side, if the instrument can be confirmed effective to be used in this research design, we need to identify on how different listening attitude could lead into homogeny result. Statistically, there was a decrease in anxiety levels and by the results of interviews and expressions shown mostly of subject's behavior showed that they felt more comfortable and pleasant.

There was a question on how we conclude that the effect acquired in posttest was mainly because of the music as an auditory stimuli yet it is possible that the respondent acquire the effect from their other sense. We could not totally guarantee that the effects is mainly cause by the music, but since we did an experiment comparing the one who listened to music and the one who didn't under approximately similar situation therefore we can conclude that music has its role in providing the effect they acquired.

From the results of unstructured interviews indicate that the subject feels more familiar with the gendhing that is played because it is part of the culture in their everyday life. Thus it can be assumed that music from the same cultural background with the subject also has a role in supporting comfort when pregnant and automatically enhancing the feeling of well-being. Therefore all efforts that succeed in reducing anxiety and stress by themselves will increase emotions that are comfortable and healthy.

\section{REFERENCES}

[1] Khalifeh H, Brauer R, Toulmin H, et al. Perinatal mental health: what every neonatologist should know. Early Hum Dev 2015;91:649-53. 10.1016/j.earlhumdev.2015.08.010 [PubMed]

[2] Kompas 13 Juni 2017. Kesejahteraan keluarga: setiap tahun 4.000-5.000 ibu meninggal saat bersalin.

[3] Leifer M. Psychological effects of motherhood: a study of first pregnancy / Myra Leifer. New York: Praeger, 1980. [Google Scholar]

[4] Elliott SA, Leverton TJ, Sanjack M, et al. Promoting mental health after childbirth: a controlled trial of primary prevention of postnatal depression. $\mathrm{Br}$ J Clin Psychol 2000; 39(Pt 3): 223-41. 10.1348/014466500163248 [PubMed] [CrossRef] [Google Scholar]

[5] Chan MF, Wong ZY, Thayala NV. The effectiveness of music listening in reducing depressive symptoms in adults: a systematic review. Complement 
Ther Med 2011; 19:332-48. 10.1016/j.ctim.2011.08.003 [PubMed] [CrossRef] [Google Scholar]

[6] Laukka P. Uses of music and psychological well-being among the elderly. J Happiness Stud 2007; 8:215-41. 10.1007/s10902-006-9024-3 [CrossRef] [Google Scholar]

[7] Shin, Hye \& Kim, Ju. 2011. Music Therapy on Anxiety, Stress and Maternalfetal Attachment in Pregnant Women During Transvaginal Ultrasound. Asian Nursing Research - ASIAN NURS RES. 5. 19-27. 10.1016/S19761317(11)60010-8. Simkin, P.T. (1986). Stress, pain, and catecholamines in labor: Part 1. A review. Birth13(4), 227-233.

[8] Simkin, P.T. 1986. Stress, pain, and catecholamines in labor: Part 1. A review. Birth 13(4), 227-233.

[9] Myers, R. E. \& Myers, S. E. 1979. Use of sedative, analgesic, and anesthetic drugs during labor and delivery: Bane or boon? American Journal of Obstetrics Gynecology.133: 83-104.

[10] Haake AB. Individual music listening in workplace settings an exploratory survey of offices in the UK. Music Sci 2011;15:107-29. [Google Scholar]

[11] McCaffrey R. Music listening: its effects in creating a healing environment. J Psychosoc Nurs Ment Health Serv 2008;46:39-44. [PubMed] [Google Scholar]

[12] Hanser, S. B., Larson, S. C., \& O'Connell, A. S. 1983. The effect of music on relaxation of expectant mothers during labor. Journal of Music Therapy, 20(2), 50-58.

[13] Salk, L. 1973. The role of the heart in the relations between mother and infant. Scientific American, 228 (5), 24-29.

[14] Gyesaw NYK, Ankomah A. Experiences of pregnancy and motherhood among teenage mothers in a suburb of Accra, Ghana: a qualitative study. Int J Women's Health. 2013;5:773-80. [PMC free article] [PubMed] [Google Scholar]

[15] Abbott A. 2002. Music, maestro, please! Nature. 416:12-14.

[16] Zatorre R, McGill J. 2005. Music, the food of neuroscience? Nature. 434:312-315.

[17] Rauscher FH, Robinson KD, Jens JJ. 1998. Improved maze learning through early music exposure in rats. Neurol Res. 20:427-432.

[18] Batt-Rawden KB, DeNora T, Ruud E. Music Listening and Empowerment in Health Promotion: A Study of the Role and Significance of Music in Everyday Life of the Long-term Ill. Nordic Journal of Music Therapy 2005;14:120-36. 10.1080/08098130509478134 [CrossRef] [Google Scholar]

[19] Skånland MS. Everyday music listening and affect regulation: the role of MP3 players. Int J Qual Stud Health Well-being 2013;8:20595 10.3402/qhw.v8i0.20595 [PMC free article] [PubMed] [CrossRef] [Google Scholar]

[20] Secoli SR, Teixeira NA. 1998. Chronic prenatal stress affects development and behavioral depression in rats. Stress. 2:273-280. 
[21] Drago F, Di Leo F, Giardina L. 1999. Prenatal stress induces body weight deficit and behavioural alterations in rats: the effect of diazepam. Eur Neuropsychopharmacol. 9:239-245.

[22] Williams MT, Hennessy MB, Davis HN. 1998. Stress during pregnancy alters rat offspring morphology and ultrasonic vocalizations. Physiol Behav. 63:337-343

[23] Spielberger, C. D. 1989. State-Trait Anxiety Inventory: Bibliography (2nd ed.). Palo Alto, CA: Consulting Psychologists Press.

[24] Beck, A.T., Ward, C. H., Mendelson, M., Mock, J., \& Erbaugh, J. 1961. An inventory for measuring depression. Archives of General Psychiatry, 4, 561571.

[25] Zahra BM, Elham R. 2014. The Prevalence of Depression in Pregnant Women with Sleep Disorder. J Psychiatry 17:157. doi: 10.4172/Psychiatry.1000157 